\title{
NITROUS OXIDE: TRENDS AND GLOBAL MASS BALANCE OVER THE LAST 3000 YEARS
}

\author{
by
}

\author{
M.A.K. Khalil and R.A. Rasmussen
}

(Institute of Atmospheric Sciences, Oregon Graduate Center, Beaverton, Oregon 97006, U.S.A.)

\begin{abstract}
We analyzed ice cores from both northern and southern polar regions to determine the concentrations of nitrous oxide in the pre-industrial and ancient atmospheres from about 150 years to 3000 years B.P. We found that the pre-industrial concentration of nitrous oxide remained constant over the period we studied and that the average atmospheric concentration was $285 \pm 1$ ppb volume $(90 \%$ confidence limits), representing about $2100 \mathrm{Tg}$ $\left(2100 \times 10^{12} \mathrm{~g}\right)$ of $\mathrm{N}_{2} \mathrm{O}$ in the atmosphere, whereas the average concentration in 1984 was about 307 ppb volume or $2260 \mathrm{Tg}$. This is a change of $22 \mathrm{ppb}$ volume $(160 \mathrm{Tg})$, or about $8 \%$, between pre-industrial and present times. Now the rate of change is between 0.7 and $0.9 \mathrm{ppb}$ volume/year or 5 and $6.5 \mathrm{Tg} /$ year, which is a slow increase of about $0.3 \%$ per year. The changes observed are probably caused by increasing use of fossil fuels, particularly coal and oil, and perhaps to a lesser extent by the use of nitrogen fertilizers in recent years. The atmospheric lifetime of $\mathrm{N}_{2} \mathrm{O}$ is probably between 100 and 150 years. The pre-industrial concentrations, present levels, and a lifetime of 100 years are consistent with natural sources, mostly soils and oceans, of about $22 \mathrm{Tg} /$ year and the present anthropogenic sources of about $8.7 \mathrm{Tg} /$ year. In the next 50 years we expect nitrous oxide levels to reach $360-390 \mathrm{ppb}$ volume, or about $16-25 \%$ more than present.
\end{abstract}

\section{INTRODUCTION}

Nitrous oxide $\left(\mathrm{N}_{2} \mathrm{O}\right)$ is a primarily natural but persistent trace gas in the Earth's atmosphere. In recent years human activities have increased its global abundance. Still higher concentrations of $\mathrm{N}_{2} \mathrm{O}$ are expected in the future and they may add to the global warming from the increasing levels of $\mathrm{CO}_{2}, \mathrm{CH}_{4}$, and other trace gases. Moreover, $\mathrm{N}_{2} \mathrm{O}$ may deplete the stratospheric ozone layer, thus further affecting the global environment (see WMO 1986, Ramanathan and others 1985). In this paper we discuss the concentrations of $\mathrm{N}_{2} \mathrm{O}$ in the pre-industrial atmosphere of several hundred to several thousand years ago, when human activities had not affected its global distribution. These concentrations are deduced from analyses of air trapped in bubbles of polar ice.

All the known sources of nitrous oxide are at the Earth's surface. The natural sources include microbial processes in the world's oceans and continents. Burning of fossil fuels and the use of nitrogen fertilizers are among the most significant anthropogenic sources. Once released, nitrous oxide remains in the atmosphere for a long time. Current estimates of its atmospheric lifetime range from 100 to 150 years. It is removed primarily in the stratosphere by photolysis and also by reacting with $\mathrm{O}\left({ }^{1} \mathrm{D}\right)$ (excited oxygen) atoms. In the pre-industrial atmosphere, we believe that the annual production and destruction of nitrous oxide were nearly balanced for long periods. Now there is an excess of $\mathrm{N}_{2} \mathrm{O}$ every year, produced by anthropogenic activities. This excess is causing a slow but steady build-up of $\mathrm{N}_{2} \mathrm{O}$ in the atmosphere. The analysis of polar ice cores to determine the concentration of $\mathrm{N}_{2} \mathrm{O}$ in the atmosphere over the last several thousand years provides information on its natural annual emissions and the effect of human activities on its cycle and global distribution.

The plan of our paper is to discuss, in section 2, the data on pre-industrial levels of $\mathrm{N}_{2} \mathrm{O}$, including an analysis of trends and distribution from 3000 years ago to the present. The global sources and removal of $\mathrm{N}_{2} \mathrm{O}$ are discussed in section 3, along with the implications of the low concentrations found in the polar ice cores. The conclusions are summarized in section 4 .

\section{PRE-INDUSTRIAL CONCENTRATIONS, TRENDS, AND DISTRIBUTION}

\subsection{Methods}

We chose samples from the Crête and Camp Century cores from the Arctic and from the Byrd Station core, Antarctica. The ice was kept frozen until analysis. Typical samples were about $15 \mathrm{~cm}$ long and the outer $1-3 \mathrm{~cm}$ were scraped off to avoid surface contamination. A sample thus prepared was sealed in an internally electro-polished stainless-steel container designed for the experiment. While the ice was still frozen, the chamber was flushed and pressurized with Helium to 1000 Torr. Then the ice was melted and the concentrations of $\mathrm{N}_{2} \mathrm{O}, \mathrm{CH}_{4}, \mathrm{~N}_{2}, \mathrm{O}_{2}, \mathrm{CCl}_{3} \mathrm{~F}$, and other gases were measured in the air above the melt water. The concentrations of $\mathrm{N}_{2} \mathrm{O}$ and $\mathrm{CCl}_{3} \mathrm{~F}$ were determined by electron-capture gas chromatography (EC/GC) (Rasmussen and Khalil 1980). A mass-balance model, for amounts in the water and the space above, was used to calculate the concentration of $\mathrm{N}_{2} \mathrm{O}$ in the air extracted from the ice-core sample. The measurements of $\mathrm{CCl}_{3} \mathrm{~F}(\mathrm{~F}-11)$ served as an index of contamination, since this chlorofluorocarbon is entirely man-made and did not exist in the atmosphere at the times represented by our samples. Indeed, in many samples no detectable concentrations of F-11 were found ( $<5 \mathrm{ppt}$ volume). We have discussed these procedures in detail in our earlier paper describing the measurements of methane in the ice cores (Rasmussen and Khalil 1984). The measurements of nitrous oxide discussed here and of methane, reported earlier, were made in 1983 on the same samples. The data for $\mathrm{N}_{2} \mathrm{O}$ are tabulated in the Appendix and can be compared directly with the results reported for methane in our earlier paper (Rasmussen and Khalil 1984).

The age of the air in the bubbles is less than the age of the ice from which it is extracted, because it takes many years for bubbles to seal after the snow has fallen. Moreover, the air trapped in the bubbles probably represents the average atmospheric concentrations of trace gases over several years, perhaps even decades, depending on the efficiency of the mixing of the atmospheric air and the air deep in the firn layer of the polar regions. These processes make it difficult to estimate accurately the age of the air in the bubbles compared to the age of the surrounding ice, which is better known. We have taken the age of the air to be 90 years less than the surrounding ice, which represents the average time for the transition from firn to ice. This quantity is variable, as shown by the work of Schwander and Stauffer (1984), and making accurate estimates of the firn-to-ice transition is an active area of research; however, the variability of this transition time does not significantly affect our conclusions (see also 
Nitrous Oxide
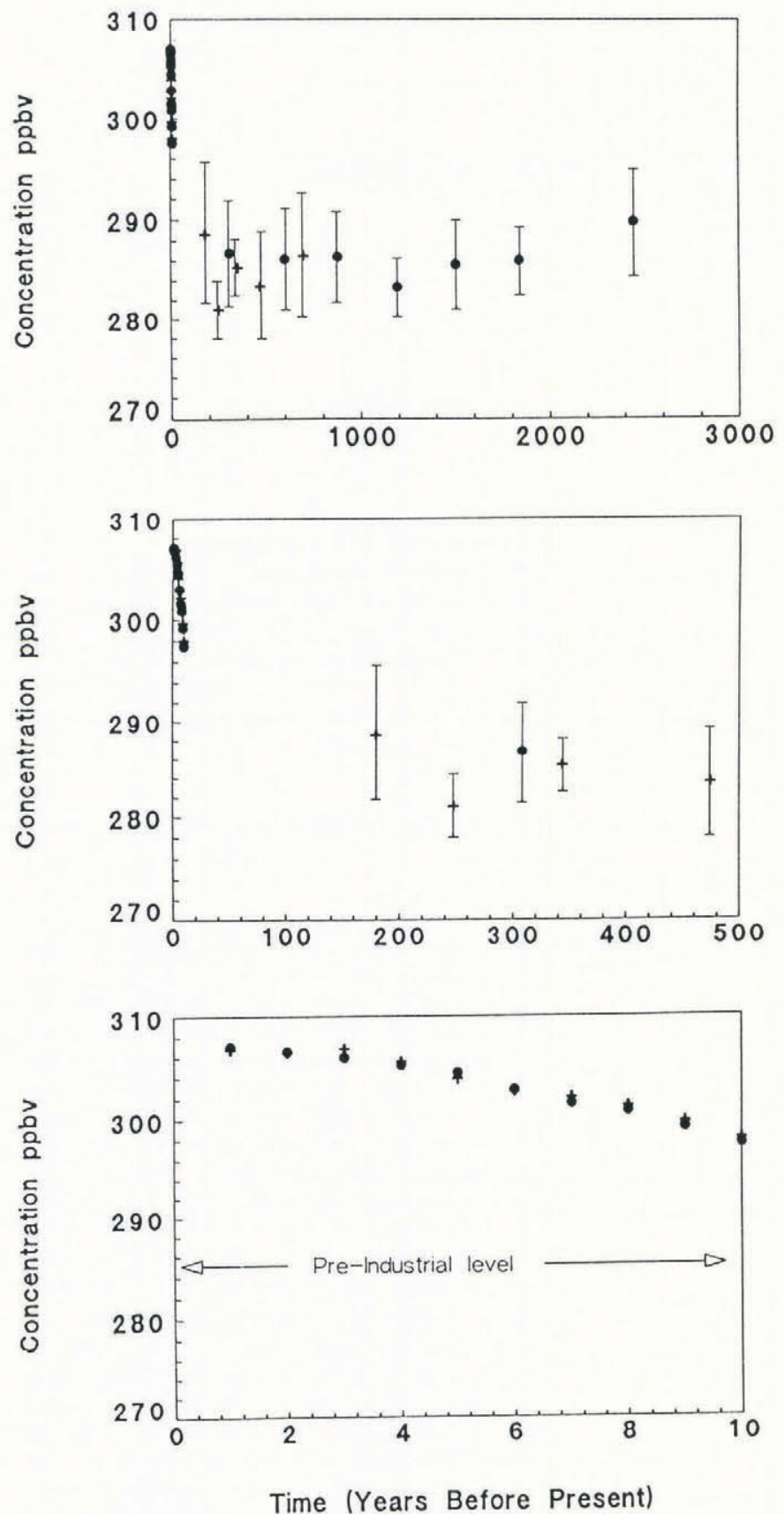

Fig.1. Concentrations of nitrous oxide over the last 3000 years. The ice-core measurements are averaged over 50-400 year periods to estimate mean concentrations and their uncertainties as tabulated in the Appendix, Table A.3. + designates data from the Arctic and $\bullet$ is used for data from the Antarctic. The first panel shows all the data, the next one contains data only for the last 500 years, and the final panel shows results from direct atmospheric measurements over the last decade (Rasmussen and Khalil 1986). The concentration has risen from about $285 \mathrm{ppb}$ volume in the pre-industrial atmosphere to about $307 \mathrm{ppb}$ volume in 1985 .

Appendix, section A.4). The depths are tabulated in the Appendix so that the data may be re-examined if the ages can be estimated more accurately.

\subsection{Concentrations}

The data are quite variable, with only a few measurements in each century; therefore we took averages over 50-400-year periods (see Appendix, Tables A.2-A.3). We estimated the variability of the concentrations as $90 \%$ confidence limits of the mean values. The results are shown in Figure 1, which also includes the concentrations measured in the present atmosphere over the last decade (Table A.1). The mean concentrations and $90 \%$ confidence limits are plotted at the average time when samples were taken. The figure includes the results of all measurements in the first panel, spanning about 3000 years, then in the next panel we show an expanded view of the last 500 years, and finally of the last 10 years as in Rasmussen and Khalil (1986).

We estimate that the average concentration of $\mathrm{N}_{2} \mathrm{O}$ in the pre-industrial atmosphere was about $285 \pm 1 \mathrm{ppb}$ volume, which agrees well with the $289 \pm 6 \mathrm{ppb}$ volume reported by Pearman and others (1986) for the period between A.D. 1600 and 1800 . The two data sets are not from the same locations or periods, which may explain some of the differences. The data of Pearman and others (1986) are from an Antarctic core and span a period as recent as 1940 and go back about 400 years before present, whereas our data are from both poles, but we have almost no data from Antarctica over the last 400 years. The \pm values here, and throughout our paper, are $90 \%$ confidence limits of the mean.

One $\mathrm{Tg}$ of nitrous oxide in the atmosphere is approximately equivalent to $0.1368 \mathrm{ppb}$ volume, assuming that there are about $10^{44}$ molecules of air in the atmosphere. The total amount of $\mathrm{N}_{2} \mathrm{O}$ in the pre-industrial atmosphere therefore turns out to be about $2100 \mathrm{Tg}$, based on an average concentration of $285 \mathrm{ppb}$ volume, and there are about $2260 \mathrm{Tg}$ in the present atmosphere (307 ppb volume, 1984).

\subsection{Trends}

No systematic trends were detected in the data spanning the last 150-3000 years. We believe that all our data are from times before human activities could have influenced the cycle of nitrous oxide. Our latest data are five measurements from the Arctic that span the last 160-200 years. The average concentration during this period was $289 \pm 7 \mathrm{ppb}$ volume, which is about $5 \pm 6 \mathrm{ppb}$ volume greater than the average concentration for the rest of the data from the Arctic ice cores. The difference, however, is not statistically significant. Data from the Antarctic ice core are for much earlier times, in which we found no evidence of trends.

We also analyzed the data of Pearman and others (1986), which, although not as detailed, represent more recent times. We found that there were no significant trends up to about A.D. 1910. The four latest measurements representing atmospheric concentrations around 1940 appeared to be significantly higher $(\alpha<0.05)$ than the rest of the data, suggesting that by 1940 some change in $\mathrm{N}_{2} \mathrm{O}$ may have occurred; however, we are not able, on the basis of the reported measurements, to make an estimate of the change.

We conclude from our data that there was no significant change in $\mathrm{N}_{2} \mathrm{O}$ concentration between 3000 years B.P. and at least up to the mid-nineteenth century. From the results of Pearman and others (1986), it appears that the concentration of $\mathrm{N}_{2} \mathrm{O}$ did not start increasing until some time after the turn of the century. These results agree with the explanation that the present increase in $\mathrm{N}_{2} \mathrm{O}$ is caused primarily by fossil-fuel combustion and possibly by the use of nitrogen fertilizers (Weiss 1981, Khalil and Rasmussen 1983, Hao and others 1987). We used a mass-balance equation, to be discussed later, and recent estimates of $\mathrm{N}_{2} \mathrm{O}$ production from the burning of coal and oil (Hao and others 1987), and calculated that by 1900 the concentration of $\mathrm{N}_{2} \mathrm{O}$ would have increased by only $1.5 \mathrm{ppb}$ volume, assuming an atmospheric lifetime of between 100 and 150 years. Such a small change would be undetectable in the measurements. By 1940, however, human activities should have caused the concentration to rise by about $5 \mathrm{ppb}$ volume, which is still a small change. The detection of this change will require more precise measurements of $\mathrm{N}_{2} \mathrm{O}$ in ice cores and many more measurements for recent times than have been reported until now. It is likely that $\mathrm{N}_{2} \mathrm{O}$ started increasing rapidly only in recent times, with most of the increase taking place over the last 40 years or so.

\subsection{Inter-hemispheric gradient}

Since nitrous oxide has a long lifetime in the 


\section{Frequency Distribution of NITROUS OXIDE}

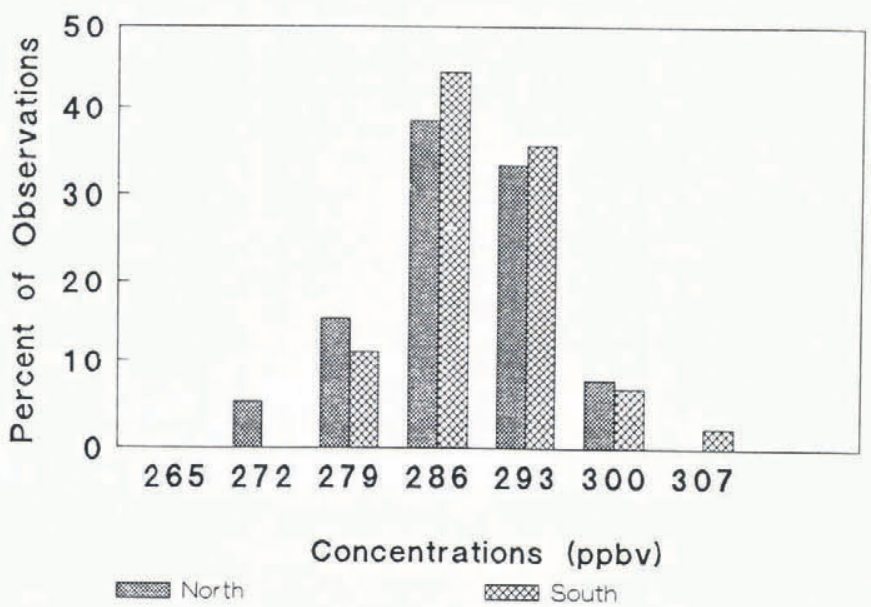

Fig.2. The frequency distribution of $\mathrm{N}_{2} \mathrm{O}$ concentrations from Antarctic and Arctic ice cores. The average concentration is $285 \pm 1 \mathrm{ppb}$ volume $(90 \%$ confidence limit of the mean).

atmosphere and because its sources are distributed all over the Earth's surface, the inter-hemispheric gradient, which is the difference of mean concentrations in the northern and southern hemispheres, is very small. It is small in both the pre-industrial and the present atmospheres; however, in recent times human activities may have reversed this gradient. In the natural pre-industrial atmosphere the concentration in the Southern Hemisphere may have been slightly higher than in the Northern Hemisphere (Mahlman and others 1986), whereas now there is slightly more in the Northern Hemisphere. The pole-to-pole gradient, which is larger than the average inter-hemispheric gradient, is defined by Equation 1:

$$
\Delta=\left(C_{n}-C_{s}\right)
$$

where $C_{n}$ and $C_{s}$ are the average concentrations in the northern and southern polar regions.

The frequency distributions of nitrous oxide concentrations in ice cores from the two polar regions are shown in Figure 2. There appears to be slightly more nitrous oxide in the Southern Hemisphere. However, the data are too variable for the difference to be statistically significant $(\alpha \leqslant 0.05)$. We estimate $\Delta$ and the $90 \%$ confidence limits to be $-1.9 \pm 2.5 \mathrm{ppb}$ volume. In the present atmosphere $\Delta$ is $+1.1 \pm 0.4 \mathrm{ppb}$ volume. The overall average concentration, as reflected in Figure 2, is $285 \pm 1 \mathrm{ppb}$ volume.

The reason for the present difference of concentrations between hemispheres is that anthropogenic industrial (and agricultural) sources are concentrated in the Northern Hemisphere. We estimated a gradient of $0.9 \mathrm{ppb}$ volume (Khalil and Rasmussen 1983), which is as observed. The reasons for the reversed gradient in the pre-industrial atmosphere are more complicated. Recent simulations of nitrous oxide, using a three-dimensional general-circulation model, showed consistently that there should be somewhat higher concentration near the South Pole, compared to the North Pole, by about 3-4 ppb volume. The conditions under which these experiments were run are more appropriate to the pre-industrial atmosphere than to the present. The cause of this asymmetry was said to be related to asymmetrial dynamical processes in the stratosphere (Mahlman and others 1986). We do not know whether our measurements reflect this phenomenon, especially since the observed asymmetry is not statistically significant and is based on highly variable and limited data.

We turn next to the budget of nitrous oxide to interpret the concentrations found in the ice cores, compared to the higher atmospheric concentrations observed in the atmosphere today.
TABLE I. SOURCES AND EMISSIONS OF NITROUS OXIDE: $\mathrm{Tg} /$ year $=10^{12} \mathrm{~g} /$ year.

$\begin{array}{ll}\text { Khalil and } & \text { McElroy and } \\ \text { Rasmussen } & \text { Wofsy (1985) } \\ \text { (1983) } & \begin{array}{l}\text { Hao and others } \\ \text { (1987) }\end{array}\end{array}$

Natural:

$\begin{array}{lcr}\text { Oceans } & 9 & 3 \\ \text { Land } & 13.4 & 12 \\ \text { Total natural } & 22.4 & 15 \\ \text { Anthropogenic } & 6.6^{*} & 9 \\ \text { Total } & 29 & 24\end{array}$

*This estimate refers to $1 / 1978$ and should be increased at about $3 \% /$ year for later years.

\section{SOURCES, SINKS, MASS BALANCES AND FUTURE CONCENTRATIONS \\ 3.1. Sources, emission rates, and lifetime}

In spite of more than a decade of research, the global emissions of nitrous oxide are still not accurately known. When there are no trends, the total amount of $\mathrm{N}_{2} \mathrm{O}$, or any other trace gas, in the atmosphere, is the product of the annual emission and its lifetime. Since the mid-1960s atmospheric measurements have pinned down the average concentration and hence the total amount of $\mathrm{N}_{2} \mathrm{O}$ in the atmosphere (Weiss 1981, Bowman and Shaw 1963, and references in Hahn and Junge 1977). Early work suggested that the lifetime of $\mathrm{N}_{2} \mathrm{O}$ was of the order of a decade or two, leading to estimates of large annual emissions to account for the observed concentrations (Hahn and Junge 1977, McElroy and others 1976). Neither large annual emissions nor the processes for removing such amounts were found. Estimates of the annual removal of $\mathrm{N}_{2} \mathrm{O}$ by the known mechanisms suggested that its lifetime may be very long, probably in the range of 100-150 years, which has led to the present view that the global annual emissions of $\mathrm{N}_{2} \mathrm{O}$ are only $24-30 \mathrm{Tg} /$ year $\left(1 \mathrm{Tg}=10^{12} \mathrm{~g}\right)$.

For the analysis of the ice-core data and present trends we will use our earlier estimates of global emissions of $\mathrm{N}_{2} \mathrm{O}$, which are shown in Table $\mathrm{I}$, along with a more recent budget by McElroy and Wofsy for comparison (quoted in WMO 1986). The sources are subdivided into natural and anthropogenic, with the natural sources further subdivided into land- and ocean-based components. Anthropogenic sources include biomass combustion, use of nitrogen fertilizers, and burning of fossil fuels, particularly coal and oil. Soils and oceans are natural sources. Our budget was derived from the previous studies, which included the works of Weiss (1981), Elkins and others (1978), McElroy and others (1976), Pierotti and Rasmussen (1976), and Weiss and Craig (1976).

Using photochemical calculations it is estimated that the atmospheric lifetime of $\mathrm{N}_{2} \mathrm{O}$ is between 100 and 150 years, caused by its reaction with $O\left({ }^{1} \mathrm{D}\right)$ and its photolysis in the stratosphere (WMO 1986, Mahlman and others 1986). Here we will assume the lifetime is 100 years, as in our previous paper (Khalil and Rasmussen 1983).

\subsection{Mass-balance calculations of past and present} concentrations and trends

Using the sources and the lifetimes discussed earlier we can calculate the expected concentrations of $\mathrm{N}_{2} \mathrm{O}$ over the last 3000 years and extend these calculations into the future.

The mass balance between sources and sinks can be written as follows:

$$
\mathrm{dC}(\mathrm{t}) / \mathrm{dt}=\mathrm{S}(\mathrm{t})-\mathrm{C}(\mathrm{t}) / \tau
$$


All the observations, sources, and sinks discussed earlier can be linked together by solving the mass-balance equation. Assuming that the natural sources have not changed over the last several thousand years, the solution of the equation is:

$$
C=\left[S_{n} \tau\right]+e^{-\eta_{t}}\left[C_{1}+\int_{0}^{t} S_{a}(v) e^{\eta v} d v\right]
$$

where $\eta=1 / \tau$ and $\mathrm{S}(\mathrm{t})=\mathrm{S}_{\mathrm{n}}+\mathrm{S}_{\mathrm{a}}$. The first term represents the natural level of $\mathrm{N}_{2} \mathrm{O}\left(\mathrm{C}_{\mathrm{n}}=\mathrm{S}_{\mathrm{n}} \tau\right)$. The value of this term is deduced from the ice-core measurements discussed earlier (=285 ppb volume). The second term reflects the growing influence of human activities, where $C_{1}$ is the contribution from anthropogenic sources at time $\mathrm{t}=0$. We describe the anthropogenic source by a logistic equation:

$$
\mathrm{dS}_{\mathrm{a}} / \mathrm{dt}=\mathrm{BS}_{\mathrm{a}}\left(\mathrm{A}-\mathrm{S}_{\mathrm{a}}\right)
$$

which has the following solution:

$$
\begin{aligned}
& S_{a}=\frac{A K e^{\alpha t}}{1+K e^{\alpha t}} \\
& K=\frac{S_{p} e^{-\alpha t} p}{A-S_{p}}
\end{aligned}
$$

where $\alpha=\mathrm{BA}, \mathrm{K}$ is a dimensionless constant of integration determined entirely by $S_{p}$, which represents the present (1987) annual anthropogenic emissions, and by $T_{p}$, the present time $(=500$ years $)$. This model provides a means for taking present estimates of anthropogenic emissions and calculating the emissions at earlier times until human activities contribute insignificant amounts to the global cycle of $\mathrm{N}_{2} \mathrm{O}$, and for extrapolating the anthropogenic emissions into the future. Time " $\mathrm{t}$ " in Equations $3-5$ is taken to be $t=$ time (in A.D.) -1487 , so that $t=$ zero 500 years ago, it is $500\left(t_{p}\right)$ at present and is extrapolated into the future to 613 , which represents A.D. 2100 .

Here is how we estimated the values of the paremeters $\mathrm{A}, \mathrm{B}$, and $\mathrm{K}$ needed to solve the equation. We assume that $\mathrm{A}=3 \mathrm{ppb}$ volume/year. It represents the most that anthropogenic activities can contribute in the future. This limit is suggested by expected population growth (Ehrlich and others 1977). The value of $B$ is chosen to make the present rate of increase of anthropogenic emissions about $3 \% /$ year (see Hao and others 1987). Under this constraint, the value of $B$ is found to be $0.0167 / \mathrm{ppb}$ volume from Equation 4. $\mathrm{K}$ is calculated from Equation $5 \mathrm{~b}$ by taking the present (1987) anthropogenic source to be $8.7 \mathrm{Tg} /$ year (1.18 ppb volume/year), which represents a $3 \% /$ year increase over the value for $1 / 1978$ given in Table I. The value $K$ turns out to be $9 \times 10^{-12}$. The resulting function describing the emissions agrees well with estimates of the use of coal and oil over the last 50 years or so (see Hao and others 1987).

The solution of Equations $2-5$ is plotted in Figure 3, which shows the overall agreement between the observed and calculated concentrations in the first panel, an expanded view in the second panel spanning approximately the last 400 years, a third panel demonstrating that concentrations started increasing recently, and finally a panel giving the atmospheric concentrations over the last decade. The model for the anthropogenic emissions was extended to estimate the build-up of $\mathrm{N}_{2} \mathrm{O}$ in the future.

\subsection{Future concentrations}

There is a practical need to estimate the future concentrations of nitrous oxide and other gases so that we can accurately assess their potential effects on the environment. Global warming or depletion of the stratospheric ozone layer depends critically on the build-up of trace gases that has yet to occur. Although there is no certain way to predict future concentrations, a mass-balance model such as the one discussed earlier isolates natural and anthropogenic sources, and then the anthropogenic sources
Nitrous Oxide

Mass Balance Model
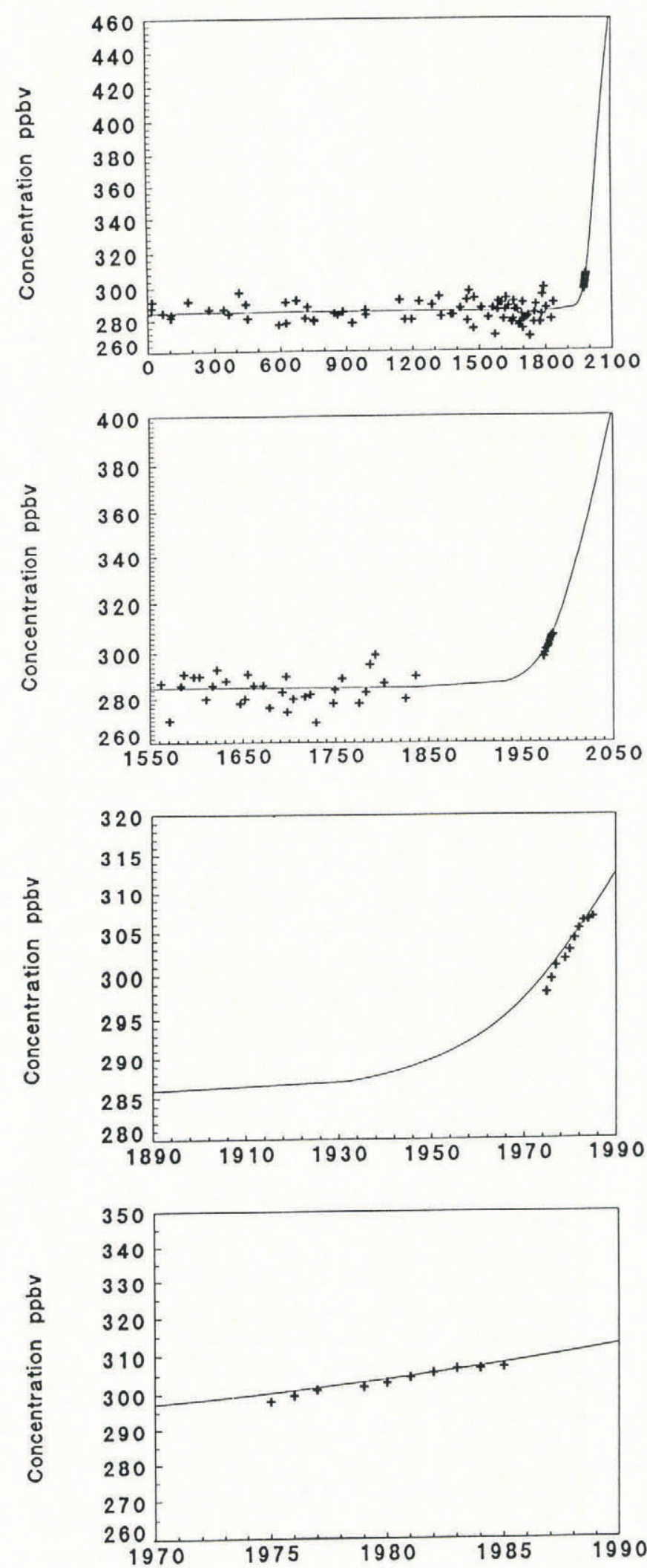

Fig.3. Measured concentrations in ice cores and in the present atmosphere are shown; concentrations were calculated with a global mass-balance model assuming an atmospheric lifetime of 100 years, and sources as described by Khalil and Rasmussen (1983) and in the text. Significant changes appear to have started recently, as shown in the third expanded panel. Other combinations of sources and lifetimes may also explain the observations; however, such combinations are not likely to differ greatly from those discussed here. 
are increased according to expected changes in global industrial, agricultural, economic, or social conditions, or changes in population. We calculated possible future concentrations by extending the source function of Equation 5 to future times.

We estimate that 50 years from now the concentration of $\mathrm{N}_{2} \mathrm{O}$ would be about $390 \mathrm{ppb}$ volume, assuming that the lifetime is 100 years and the anthropogenic sources increase according to a logistic equation limited by population, as discussed in the previous section. In our earlier paper (Khalil and Rasmussen 1983) we had used the same type of model, and for similar rates in increase of present anthropogenic sources we had estimated the concentration to be $370 \mathrm{ppb}$ volume in 509 years (taking the case of $\alpha=\mathrm{BA}=0.06$, which gives $\mathrm{dS}_{\mathrm{a}} / \mathrm{dt}$ in $1978=0.04$; see Appendix, section A.4). The previous estimates assumed a smaller anthropogenic source $(0.72 \mathrm{ppb}$ volume/year), a lower ultimate limit $(\mathrm{A}=2.16 \mathrm{ppb}$ volume $/$ year $)$, and a lower pre-industrial concentration of $282 \mathrm{ppb}$ volume, which explains the somewhat lower estimated future concentrations. Other estimates of future concentrations are discussed by Weiss (1981), who assumed that anthropogenic sources would increase exponentially at $3.5 \%$ year and therefore estimated concentrations of $350 \mathrm{ppb}$ volume by about the year 2020 . Exponentially increasing sources cannot be extended for long periods before they result in very high concentrations. Hao and others (1987) assumed that anthropogenic sources would continue to increase linearly at present rates and thus calculated that $\mathrm{N}_{2} \mathrm{O}$ concentrations would reach levels a little less than $360 \mathrm{ppb}$ volume in 50 years, which they said was a conservative estimate. Both $\mathrm{Hao}$ and others (1987) and Weiss (1981) assumed that the atmospheric lifetime of $\mathrm{N}_{2} \mathrm{O}$ is 150 years. Of the three models to estimate future concentrations, ours is the only one in which growth of anthropogenic sources is limited. The results of these models suggest that 50 years from now the concentration of $\mathrm{N}_{2} \mathrm{O}$ will be $360-390 \mathrm{ppb}$ volume, or about $16-25 \%$ more than the present, which is a change 3-4 times larger than has taken place between now and pre-industrial times.

\section{DISCUSSION AND CONCLUSIONS}

We have shown that the pre-industrial levels of $\mathrm{N}_{2} \mathrm{O}$ were about $285 \mathrm{ppb}$ volume and that there is no evidence of any significant changes until very recent times. During the last decade atmospheric concentrations have risen steadily at about $0.3 \%$ year, and the average concentration in 1984 was about $307 \mathrm{ppb}$ volume. To explain these observations quantitatively we made two assumptions: that our previous estimates of the global annual emissions of $\mathrm{N}_{2} \mathrm{O}$ from natural and anthropogenic sources were correct and that the atmospheric lifetime of $\mathrm{N}_{2} \mathrm{O}$ is about 100 years. Next we assumed that the present anthropogenic sources can be extrapolated both backward and forward in time by a logistic growth model. Using the lifetime and the source function we then calculated the expected concentrations, which fully explain the observations shown in Figure 3. The calculated concentrations reproduce the past and present concentrations and current rate of increase. They also show that the changes being observed have taken place over recent times, becoming significant around the $1940 \mathrm{~s}$ and 1950 s.

The calculations provide a consistent framework for describing the observed concentrations of $\mathrm{N}_{2} \mathrm{O}$ in ice cores and the present atmosphere, the estimated anthropogenic and natural sources, and the atmospheric lifetime. There are, however, other combinations of emissions and lifetimes that may also explain the observations equally well. With more data the range of possibilities can be reduced.

\section{ACKNOWLEDGEMENTS}

We thank Dr P J Fraser (CSIRO-Australia) for discussions. Samples were obtained from the ice-core facility at the State Univesity of New York at Buffalo. Financial support for this work was provided in part by grants from the National Aero nautics and Space Administration (NASA, grant no. NAGW-280) and from the National Science Foundation (NSF, grant no. DPP-8207470). Additional support was provided by the Biospherics Research Corp. and by Andarz Co.

\section{REFERENCES}

Bowman R L, Shaw J H 1963 The abundance of nitrous oxide, methane and carbon monoxide in ground-level air. Applied Optics 2: 176

Ehrlich P R, Ehrlich A H, Holdren J P 1977 Ecoscience; population, resources and environment. San Francisco, W $\mathrm{H}$ Freeman Co

Elkins J W, Wofsy S C, McElroy M B, Kolb C E, Kaplan W A 1978 Aquatic sources and sinks for nitrous oxide. Nature 275(5681): 602-606

Hahn J, Junge C 1977 Atmospheric nitrous oxide: a critical review. Zeitschrift fur Naturforschung Ser A 32: 190-214

Hao W M, Wofsy S C, McElroy M B, Beer J M, Toqan M A 1987 Sources of atmospheric nitrous oxide from combustion. Journal of Geophysical Research 92(D3): 3098-3104

Khalil M A K, Rasmussen R A 1983 Increase and seasonal cycles of nitrous oxide in the Earth's atmosphere. Tellus 35B: $161-169$

Khalil M A K, Rasmussen R A 1985 Causes of increasing atmospheric methane: depletion of hydroxyl radicals and the rise of emissions. Atmospheric Environment 19: 397-407

McElroy M B, Elkins J W, Wofsy S C, Yung Y L 1976 Sources and sinks for atmospheric nitrous oxide. Reviews of Geophysics and Space Physics 14: 143-150

Mahlman J D, Levy H II, Moxim W J 1986 Three-dimensional simulations of stratospheric $\mathrm{N}_{2} \mathrm{O}$ : predictions for other trace constituents. Journal of Geophysical Research 91(D2): 2687-2707

Pearman G I, Etheridge D, Silva F de, Fraser P J 1986 Evidence of changing concentrations of atmospheric $\mathrm{CO}_{2}$, $\mathrm{N}_{2} \mathrm{O}$ and $\mathrm{CH}_{4}$ from air bubbles in Antarctic ice. Nature 320(6059): $248-250$

Pierotti D, Rasmussen R A 1976 Combustion as a source of nitrous oxide in the atmosphere. Geophysical Research Letters 3(5): 265-267

Pierotti D, Rasmussen R A 1980 Nitrous oxide measurements in the eastern tropical Pacific Ocean. Tellus 32B: $56-72$

Ramanathan V, Cicerone R J, Singh H B, Kiehl J T 1985 Trace gas trends and their potential role in climate change. Journal of Geophysical Research 90(D3): $5547-5566$

Rasmussen R A, Khalil M A K 1980 Atmospheric halocarbons: measurements and analyses of selected trace gases. In Aitkin A C (ed) Proceedings of the NATO Advanced Study Institute on Atmospheric Ozone: Its Variation and Human Influences. Washington, DC, Department of Transportation.

Rasmussen R A, Khalil M A K 1984 Atmospheric methane in the recent and ancient atmospheres: concentrations, trends and inter-hemispheric gradient. Journal of Geophysical Research 89(D7): 11599-11605

Rasmussen R A, Khalil M A K 1986 Atmospheric trace gases: trends and distributions over the last decade. Science 232(4758): 1623-1624

Schwander J, Stauffer B 1984 Age difference between polar ice and air trapped in its bubbles. Nature 311(5981): 45-47

Weiss R F 1981 The temporal and spatial distribution of tropospheric nitrous oxide. Journal of Geophysical Resarch 86(C8): 7185-7195

Weiss R F, Craig H 1976 Production of atmospheric nitrous oxide by combustion. Geophysical Research Letters 3(12): $751-753$

WMO 1986 Atmospheric ozone 1985. Geneva, World Meteorological Organization (WMO-GORMP Report 16)

\section{APPENDIX}

\section{A.1. Atmospheric $\mathrm{N}_{2} \mathrm{O}$ over the last decade}

Table A.1 consists of the average concentrations during each year between 1975 and 1984. To obtain the average concentration for the year, we took the average of concentrations measured in January of a given year and the January of the next year (Rasmussen and Khalil 1986). 
TABLE A.1: CONCENTRATIONS OF NITROUS OXIDE OVER THE LAST DECADE (ppb volume).

$$
\begin{aligned}
& \text { North-west Pacific South Pole } \\
& \text { (lat. } 45^{\circ} \mathrm{N} \text { ) }
\end{aligned}
$$

$\begin{array}{ll}306.8 & 307.0 \\ 306.5 & 306.5 \\ 306.8 & 306.0 \\ 305.6 & 305.2 \\ 303.9 & 304.4 \\ 302.7 & 302.8 \\ 302.1 & 301.5 \\ 301.2 & 300.8 \\ 299.7 & 299.2 \\ 298.0 & 297.5\end{array}$

\section{A.2. Ice-core measurements of $\mathrm{N}_{2} \mathrm{O}$}

Table A.2 consists of the measured concentrations of nitrous oxide in the ice cores. We reported measurements of methane for the same samples in an earlier paper. Other details of the samples and their analyses are provided in the same paper (Rasmussen and Khalil 1984). The age of the air, reported in the following tables, is assumed to be 90 years less than the age of the ice from which it is extracted. The ages of the air are rounded to the nearest 10 years.

TABLE A.2. PRE-INDUSTRIAL CONCENTRATIONS OF NITROUS OXIDE FROM ICE CORES.

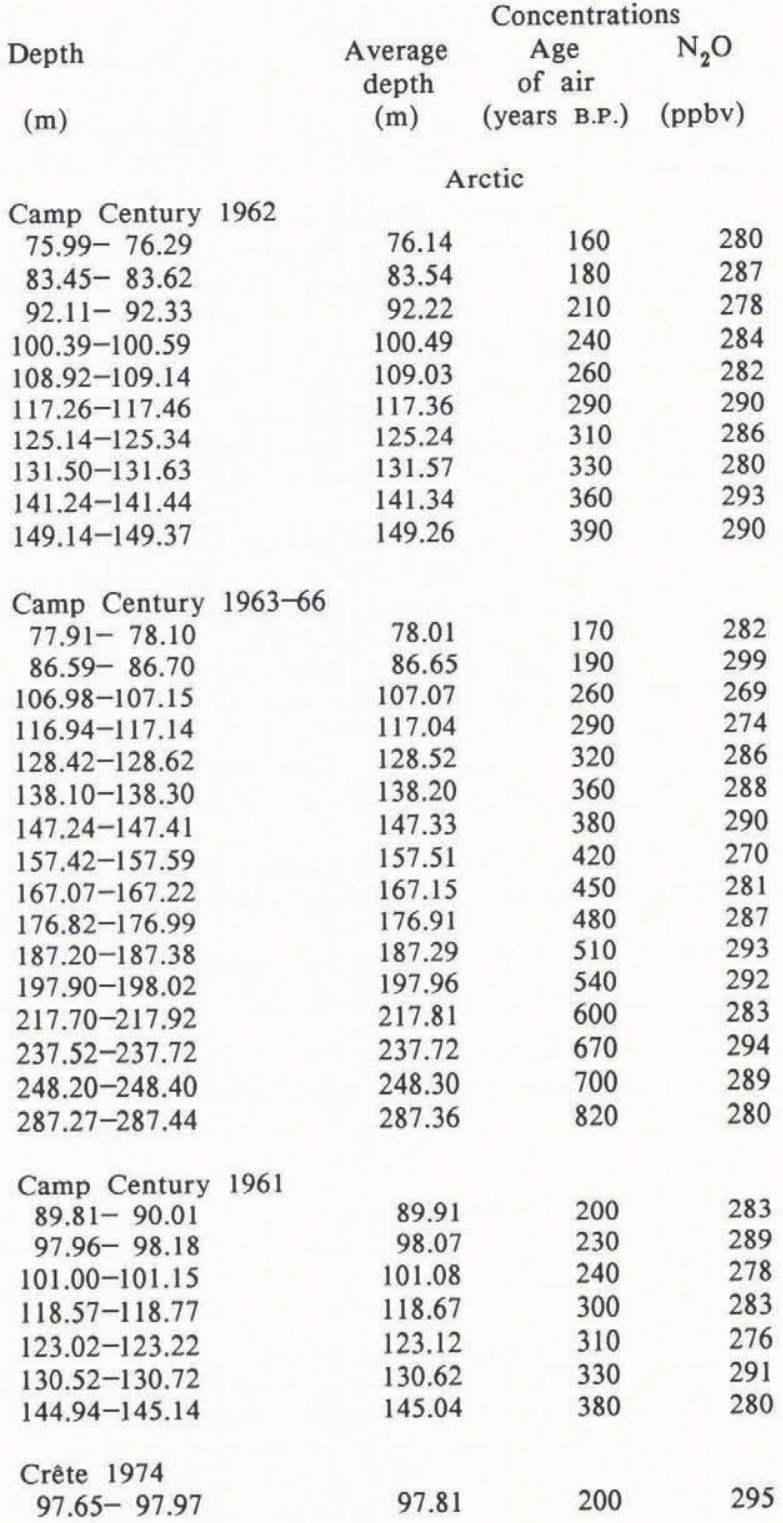




\section{8}

4.4 increase of $3 \% /$ year for anthropogenic sources in recent years, based on the work of Hao and others (1987). Other matters relevant to comparing the calculations in this paper and those given in the Tellus paper are discussed in the text.
A.4. Notes on comparisons with our previous publications: 1. Rasmussen R A, Khalil M A K 1984 Atmospheric methane in the recent and ancient atmospheres: concentrations, trends and inter-hemispheric gradient. Journal of Geophysical Research 89(D7): 11599-11605.

In the course of comparing this present paper with our earlier work on methane (Rasmussen and Khalil 1984), we discovered some errors that could lead to confusion if left uncorrected.

In table $\mathrm{A} .4$ of the $\mathrm{CH}_{4}$ paper, which is analogous to Table A.2 here, for all except the Crête 1974 core, the ages reported are not the ages of the ice as stated in the paper but are 90 years less, which corresponds to our estimated average transition time from firn to ice. In the $\mathrm{CH}_{4}$ paper, for the five measurements of the Crête 1974 core, the reported numbers are the ages of ice and 90 years should be subtracted to arrive at the age of the air. Secondly, in the $\mathrm{CH}_{4}$ paper the formula relating the depth of ice to its age is wrong for the Crête 1974 core although figure A.1 shows the correct relationship. The formula should read: $\mathrm{T}($ age B.P. $)=-29$ (years) +3.26 (years $/ \mathrm{m}) \mathrm{Z}$ (depth, $\mathrm{m})$. These errors affect only the appendix of the $\mathrm{CH}_{4}$ paper and not the conclusions of the paper.

In the $\mathrm{CH}_{4}$ paper we used the ages of the ice samples as estimated by Dr C.C. Chou of the Scripps Oceanographic Institution. Over the ranges of depths we investigated, the ages are, to a very good approximation, represented by linear functions of the form: (T(age) $=A+B Z$ (depth), where $\mathrm{A}$ and $\mathrm{B}$ are constants, as reported in the $\mathrm{CH}_{4}$ paper and corrected above for the Crête 1974 core. In this paper we have used these formulae and not the actual ages. We used $\mathrm{A}=-293$ years and $\mathrm{B}=8.67$ years $/ \mathrm{m}$ for the Byrd cores, $A=12$ years and $B=3.13$ years $/ \mathrm{m}$ for the Camp Century cores. This introduces small differences, generally around 10 years, between the reported ages of the air in Table A.2 here and in table A.4 of the $\mathrm{CH}_{4}$ paper. For a few samples of deeper ice the discrepancy may be somewhat larger. These differences do not affect our conclusions in the slightest.

Finally it should be noted that there are samples in which we did not measure $\mathrm{CH}_{4}$, and there are others for which no $\mathrm{N}_{2} \mathrm{O}$ analyses were done; however, for most samples we measured both gases.

2. Khalil M A K, Rasmussen R A 1983 Increase and seasonal cycles of nitrous oxide in the earth's atmosphere. Tellus 35B: 161-169.

In Equation 5 of our paper in Tellus and in the definition of $\alpha$, B should be $B$ as it is in Equation 4 of this paper. This typographical error could lead to confusion with $\mathrm{B}$ in equation 4 of the Tellus paper, where it represents the anthropogenic emissions at time 0 (1978). In the Tellus paper we extrapolated the concentrations of $\mathrm{N}_{2} \mathrm{O}$ into the future and therefore assumed time to be 0 in 1978 , which is the year when we first took atmospheric measure- ments.

We did not make it clear in the Tellus paper that a range of values was chosen for $\alpha$, to make the rate of increase of anthropogenic sources lie between $2 \%$ /year and $4 \% /$ year at $t=0$ (1978). This is particularly confusing since in the figure (fig.4) these calculations were compared with other calculations, using an anthropogenic source increasing exponentially at rates of 3.5 and $6 \% /$ year. This comparison was a mistake. The intention was to compare the results of the logistic model with exponentially increasing anthropogenic sources at $2-4 \% /$ year rates of increase. Therefore it should be noted that, in the Tellus paper, for $\alpha=0.035$ the rate of increase of anthropogenic emissions in 1978 , given by $1 / \mathrm{S}_{\mathrm{a}}\left(\mathrm{dS}_{\mathrm{a}} / \mathrm{dt}\right) \mid \mathrm{t}=0$, is $2.3 \% /$ year, and for $\alpha=$ 0.06 it is $4 \%$ /year. These rates should be compared with the calculations in this paper, where we adopt the rate of 